\title{
Original
}

\section{Study and Comparison of Tooth Size and Arch Length in Angle Class III Malocclusion Between Nepalese and Chinese Population}

\author{
Qu Hong1), Tan Jun'), Sambha Shrestha' ${ }^{1)}$, Zhu Enxin' ${ }^{1)}$ Tan bo $^{1)}$, Takako Shimizu ${ }^{3)}$, Keisuke Nakano4), \\ Shin Takagi ${ }^{\text {() }}$, Testuya Takamata ${ }^{3)}$ and Norimasa Okafuji ${ }^{4)}$

\begin{abstract}
${ }^{1)}$ Department of orthodontics, Dalian Medical University Stomotological College, China
${ }^{2}$ Department of stomotology, The Second Affiliated of Dalian Medical University, China

3) Department of Dental Diagnostic Sciences, Matsumoto Dental University Hospital, Shiojiri, 399-0781 Japan

4) Department of Hard Tissue Research, Matsumoto Dental University Graduate School of Oral Medicine, Shiojiri,399-0781 Japan

5) Department of Oral and Maxillofacial Reconstructive Surgery, Graduate School of Medicine,Dentistry and Pharmaceutical Sciences, Okayama University, Japan
\end{abstract}

(Accepted for publication, July 22, 2008)

\begin{abstract}
Angle class III malocclusion are very hard to treat only by orthodontic method for most adults. So in this study we have measured The mesio-distal tooth size and arch length on the dental casts of total 39 pairs (17Chinese,22Nepalese) of Angle class III malocclusion, Upper lateral incisor, upper canine and upper second premolar shows significant difference between Nepalese and Chinese $(\mathrm{P}=0.02, \mathrm{P}=.01, \mathrm{P}=.003)$. Lower teeth show no significant difference between Nepalese and Chinese. Among Nepalese male and female lower lateral incisors, second premolar molar show significant difference $(\mathrm{P}=0.035, \mathrm{P}=0.032, \mathrm{P}=0.049)$, second premolar shows significant difference between Nepalese male and female $(\mathrm{P}=0.020)$. Among Chinese male and female shows no significant difference between upper teeth while lower first molar shows significant difference $(\mathrm{P}=0.041, \mathrm{P}=0.00)$. For Nepalese OR 90.42 and AR 78.76 while for Chinese OR 89.58 and AR 78.16. No significant difference between Chinese and Nepalese OR and AR. Upper arch length for Nepalese male and female having angle class III malocclusion are 79.5 and 77 respectively. Lower arch length for Nepalese male and female with Angle class III malocclusion are 73.8 and 69.25. Among Nepalese upper arch length between male and female $(\mathrm{P}<0.05)$ shows significant difference but no significant difference between male and female in lower arch length $(\mathrm{P}>0.05)$. For Nepalese male the space lack for upper jaw is $3.7 \mathrm{~mm}$ and for lower jaw $6.6 \mathrm{~mm}$.
\end{abstract}

key words: Arch length, Bolton ratio, Class III malocclusion, Tooth size.

\section{Introduction}

The occurance of class III malocclusion is believed to be hereditary although environmental factors such as habits and mouth breathing may play a important role ${ }^{1,2)}$. The prevalence of class III malocclusion varies among different ethnic groups. In Asian societies the frequency of Class III malocclusion is higher due to a larger percentage of patients with maxillary deficiency ${ }^{3}$. The incidence of Class III malocclussion ranges between 4 to 13 percent among the Japanese ${ }^{4)}$ and 4 to 14 percent among the Chinese ${ }^{5)}$. Early detection of all types of malocclusion is very essential. El Mangoury ${ }^{6}$ ) in his study of epidemiological panorama of dental occlusion on 501 Caucasoid sample resident of Egypt found that a great number of general dentist fail to detect the Angle class III malocclusion. Anterior crossbite is not a sole diagnostic criteria for class III malocclusion because Angle

Coresponding to: Qu Hong DDS phD, Dalian Medical University Stomatological College No.9 West Segment of Lv Shun south Road DaLian, 116044, China.Tel : +86-0411-84543316, Fax. : +86-(0)41184543315,E-mail : hongqu22@yahoo.com.cn/hongqu22@hotmail.com class III type 1 (edge to edge) is more common than Angle class III type 2 (normal anterior overbite) and Angle class III type 3 (anterior cross bite).With this findings he stated that early detection of all malocclusion helps in preventive, interceptive orthodontic and dentofacial orthopedic for young patient to avoid or to minimize the occurrence of class III malocclusion at the adult stage ${ }^{6}$. There are 3 type Angle class III malocclusion s : (1)Dental (2)functional (3) skeletal

Angle class III dental and functional type of malocclusion are easier one to treat than skeletal malocclusion ${ }^{7)}$. Children usually will have dental and functional type, so if not treated on time the condition will be worse and it may turn into skeletal type, which is the most difficult and challenging one to treat. The facial profile seems concave which may need surgery ${ }^{8}$. Preventive orthodontics by its vary nature requires a continuous, long range approach. Without preventive treatment the complex time table of growth, development, tissue differentiation, reabsorbing eruption all under the influence of 
continuous functional force that can't be assure. Preventive orthodontics means a dynamic ever constant vigilance, a routine, a discipline for both doctor and patient ${ }^{8)}$ Interceptive orthodontics deal with the malocclusion as a faith accomplice, at least to minor degree. if this proper service is given with dispatch, autonomous adjustment it will restore normal occlusion.. If not treated immediately then corrective orthodontic treatment is needed. This study was done to find out the tooth size discrepancy in anterior ratio and overall ratio for class III malocclusion patients by comparing with the normal values for both Nepalese and Chinese subjects and also to find whether mandibular teeth size are larger and maxillary teeth are smaller than that of maxillary and mandibular teeth of class I normal occlusion subjects. This study was also done to compare among class III subjects of Nepalese and Chinese population to see whether any significant difference in the overall ratio and anterior ratio for these two races.

Prevalence of class III malocclusion in Nepalese is $8 \%{ }^{9}$ ) and for Chinese from $0-6$ years is $14.94 \%$, for 6-12 years is $9.65 \%$ and from 12-18 years 1 is $4.98 \%{ }^{7)}$. Mesio-distal tooth width has an anthropological significant because it provides valuable information on human evolution with technological and dietary changes ${ }^{10)}$. On a clinical level mesio-distal tooth width is correlated to the arch aliment and large tooth associated with crowded dental arches. The size and form of dental arches can have considerable implication in orthodontic diagnosis and treatment planning, affecting the space availability, dental esthetic and stability of dentition ${ }^{11)}$. G V Black ${ }^{12)}$ conduct on most classical investigation on the subject of tooth size. Investigators have strongly recommended the early detection of all classes of malocclusion ${ }^{6}$. Furthermore the endorse preventive, interceptive orthodontics and dentofacial orthopedic for young patient to avoid or at least to minimized the occurrence of class III malocclusion at the adult stage. The prevalence of class III malocclusion report to be 16.8 percent by Garner and Butt ${ }^{1)}$ children in the region of Kenya, and a 3.5 percent incidence of class III malocclusion was found in Turkey $^{13)}$. Braun at al ${ }^{14)}$ indicated that the mandibular dental arch associated with class III malocclusion are wider than class I mandibular arches beginning in premolar area .

Factors causing variation in tooth size

(1) Nutrition was discussed as main cause of retarded growth during World War II ${ }^{15)}$.

(2) Vitamin deficiencies in pregnant rats shows 2 to 8 percent reduction in mesio-distal tooth size of offspring's ${ }^{16)}$.

(3) Protein deficiency or calorie deficiency shows that tooth size was affected. Experiment was done in pigs ${ }^{17)}$

Orthodontic treatment should result in appropriate point of contact between neighboring teeth. Proportions in tooth sizes are needed to achieve this ${ }^{18,19)}$ However some discrepancies between tooth size are not apparent until the final stage of orthodontic treatment ${ }^{18,19)}$. Correct tooth size relationship between maxillary and mandibular teeth is an important factor to achieve a proper occlusal interdigitation ${ }^{20)}$. Several methods have been describe to evaluate interact tooth size relationship such as Kesling's diagonistic setup ${ }^{21)}$, Neff's anterior coefficient ${ }^{22,23)}$ and Boltons anterior ratio for six anterior teeth and overall ratio for 12 teeth $^{20,24)}$ Many factors such as heredity, growth of the bone, eruption and inclination of the teeth, external influence, function and ethnic background would affect the size and shape of dental arches ${ }^{25-28)}$ Bolton analysis is the most widely used method ${ }^{24)}$ Bolton in 1958 analyzed the relationship between the mesiodistal tooth width of maxillary and mandibular teeth by studying 55 Caucasian subjects with excellent occlusion ${ }^{29)}$. Bolton in 1958 develop a method of analyzing the mesiodistal tooth size ratio between maxillary and mandibular teeth. He conduct that it would be difficult for proper occlusal interdigition or coordination of arches in the finishing stage of treatment with out a proper mesiodistal tooth size ratio between the maxillary and mandibular teeth ${ }^{30)}$.

\section{Materials and Methodes}

\section{Sample}

A samples of total 39 subjects (17 Chinese and 22 Nepalese ) with angle class III malocclusion were selected from the patient's record files. 17 Chinese (10 male and 7 female) subjects were collected from faculty of Dentistry, Department of Orthodontics, Dalian Medical University, China. 22 Nepalese (12 male and 10 female) subjects were collected from Department of Orthodontics, faculty of Dentistry, Samaj Dental Hospital, Orthodontic Centre Kathmandu Plaza, Nepal.. The subjects age range from 15 to 24 years for both Chinese and Nepalese .

The inclusion criteria

(1) Bilateral class III molar relationship in centric occlusion with the cups tip of the maxillary second premolar from the buccal groove of the mandibular first molar.

(2) Class III permanent canine relationship.

(3) All subjects having all anterior teeth overlapped by lower anterior teeth.

(4) All teeth were present except third molar.

(5) All permanent teeth fully erupted to the occlusal plane.

(6) No history of trauma, any maxillofacial surgery, any previous orthodontics or any post-orthodontic treatment.

(7) No medical history.

(8) All casts were of good quality with no evidences of air bubbles, no tooth fractures, no abnormal shape.

(9)No caries, and no attritions.

\section{Materials}

(1) Dental stone (Nepalese) made in India (Densply), Dental stone (Chinese) made in China (Heraeus).

(2) Vernier caliper (made in Germany, $0.1 \mathrm{~mm}$ accuracy).

(3) SPSS version 11.5 (software package for the social science).

(4) Computer (made in China, HP Compaq).

(5) Brass wire of 0.25 inch diameter.

\section{Cast measurement}

Measurements were made directly on plaster casts. The following 
Qu Hong et al.: Nepalese and Chinese Tooth Size and Arch Length in Angle Cass III Malocclusion

variables were measured.

(1) Mesiodistal tooth width

The caliper beaks were insert from the facial aspect of the tooth and held perpendicular to the long axis of the tooth. The beaks were then closed until gentle contact with the predetermined contact point of the tooth was made The measurements included the mesiodistal width of all twelve maxillary and twelve mandibular teeth from right first permanent molar to the left first permanent molar on 39 pairs of casts.

(2) Arch length: (with brass wire of 0.25 inch diameter)

The distance from the distal surface of the second premolar to the distal surface of the lateral incisor and from there to the midline. This was repeated on both sides. These values were computed to determine the arch length in each arch.

\section{Bolton analysis}

(1) AR = Sum of the mesiodistal width of mandibular six (canine to canine) $\times 100 /$ Sum of the mesiodistal width of maxillary six (canine to canine) .

(2) $\mathrm{OR}=$ Sum of the mesiodistal width of mandibular twelve (first molar to first molar) $\times 100 /$ Sum of the mesiodistal width of maxillary twelve (first molar to first molar).

\section{Descriptive statistic}

The data of the present study were subjected to statistical analysis utilizing a computer program SPSS, Statistical Package for the Social Science, version 11.5. The mean and standard deviation for each tooth in both races (Chinese and Neplease) were calculated. Mesiodistal tooth width comparison between Chinese and Neplease were made for each tooth using Statistical analysis were performed with a software package (Version 11.5, SPSS). Mean, standard deviation, minimum, maximum, coefficient of correlation, independent t-test were calculated.

Table 1: Mean and SD of upper teeth Nepalese. (SD: Standard deviation)

\begin{tabular}{llllc}
\hline Teeth & Gender & Mean & SD & Significance \\
\hline U1 & M & 8.70 & 1.18 & 0.541 \\
& F & 8.83 & 0.61546 & \\
U2 & M & 7.30 & 0.63246 & 0.121 \\
& F & 6.75 & 0.86603 & \\
& & & & \\
U3 & M & 7.95 & 0.79757 & 0.861 \\
& F & 7.37 & 0.82916 & \\
U4 & M & 7.20 & 0.67495 & 0.901 \\
& F & 7.12 & 0.74239 & \\
U5 & M & 6.75 & 0.58926 & 0.064 \\
& F & 7.20 & 1.09665 & \\
U6 & M & 11.05 & 0.55025 & 0.235 \\
& F & 10.71 & 0.72169 & \\
\hline
\end{tabular}

\section{Tooth size}

\section{Result}

Upper lateral incisor, upper canine and upper second premolar shows significant difference between Nepalese and Chinese $(\mathrm{P}=0.02$, $\mathrm{P}=01, \mathrm{P}=0.03$ respectively). Lower teeth show no significant difference between Nepalese and Chinese. Among Nepalese male

Table 2: Mean and SD of lower teeth Nepalese (SD: Standard Deviation)

\begin{tabular}{cllcc}
\hline Teeth & Gender & Mean & SD & Significance \\
\hline L1 & M & 5.7000 & 0.42164 & 0.119 \\
& F & 5.5000 & 0.56408 & \\
L2 & M & 6.3000 & 0.53748 & 0.229 \\
& F & 5.9583 & 0.45017 & \\
L3 & M & 7.0500 & 0.72457 & 0.694 \\
& F & 6.4167 & 0.46872 & \\
L4 & M & 7.3000 & 0.58689 & 0.336 \\
& F & 6.7083 & 0.86493 & \\
L5 & M & 7.2500 & 0.54006 & 0.057 \\
& F & 7.3333 & 1.00755 & \\
L6 & M & 11.4000 & 0.56765 & 0.163 \\
& F & 10.8333 & 0.44381 & \\
\hline
\end{tabular}

Table 3: Mean and SD of upper teeth Chinese ( SD :Standard Deviation)

\begin{tabular}{lllll}
\hline Teeth & Gender & Mean & SD & Significance \\
\hline U1 & M & 8.9318 & 0.52549 & 0.603 \\
& F & 8.6667 & 0.51640 & \\
U2 & M & 7.0000 & 0.38730 & 0.267 \\
& F & 6.7917 & 0.45871 & \\
U3 & M & 8.0227 & 0.50565 & 0.259 \\
& F & 7.8333 & 0.76920 & \\
U4 & M & 7.5455 & 0.85013 & 0.102 \\
& F & 7.2917 & 0.40052 & \\
U5 & M & 7.0682 & 0.65279 & 0.038 \\
& F & 7.0417 & 0.24580 & \\
U6 & M & 11.5455 & 0.72300 & 0.011 \\
& F & 11.0833 & 0.20412 & \\
\hline
\end{tabular}

and female lower lateral incisors, second premolar and lower molar show significant difference $(\mathrm{P}=0.035, \mathrm{P}=0.032, \mathrm{P}=0.049)$ (table 2). Upper second premolar shows significant difference between Nepalese male and female ( $\mathrm{P}=0.020)$ (table 1$)$. Among Chinese male and female show no significant difference between upper teeth (Table 3 ), while lower canine and lower first molar shows significant difference ( $\mathrm{P}=0.041, \mathrm{P}=0.001)$ ( Table 4).

\section{Arch length}

Mean upper arch length for Nepalese male and female having Angle 
Table 4: Mean and SD of lower teeth Chinese (SD: Standard Deviation)

\begin{tabular}{lllll}
\hline Teeth & Gender & Mean & SD & Significance \\
\hline L1 & M & 5.8409 & 0.55083 & 0.514 \\
& F & 5.3333 & 0.60553 & \\
L2 & M & 6.0000 & 0.48734 & 0.335 \\
& F & 5.9167 & 0.68313 & \\
L3 & M & 6.8636 & 0.58485 & 0.274 \\
& F & 6.9667 & 0.38297 & \\
L4 & M & 7.2500 & 0.60208 & 0.642 \\
& F & 7.1667 & 0.7692 & \\
L5 & M & 7.2500 & 0.62249 & 0.746 \\
& F & 7.5000 & 0.63246 & \\
L6 & M & 11.4545 & 0.90704 & 0.095 \\
& F & 11.0833 & 0.37639 & \\
\hline
\end{tabular}

Table 5: arch length mean of Nepalese and Chinese male and female.

\begin{tabular}{lcc}
\hline Country/gender & $\begin{array}{c}\text { Upper arch length } \\
\text { mean(mm) }\end{array}$ & $\begin{array}{c}\text { Lower arch length } \\
\text { mean(mm) }\end{array}$ \\
\hline Nep m & 79.5000 & 73.8 \\
Nep f & 77.0000 & 69.25 \\
Ch m & 76.1818 & 64.3636 \\
Ch f & 76.5000 & 65.1667 \\
\hline
\end{tabular}

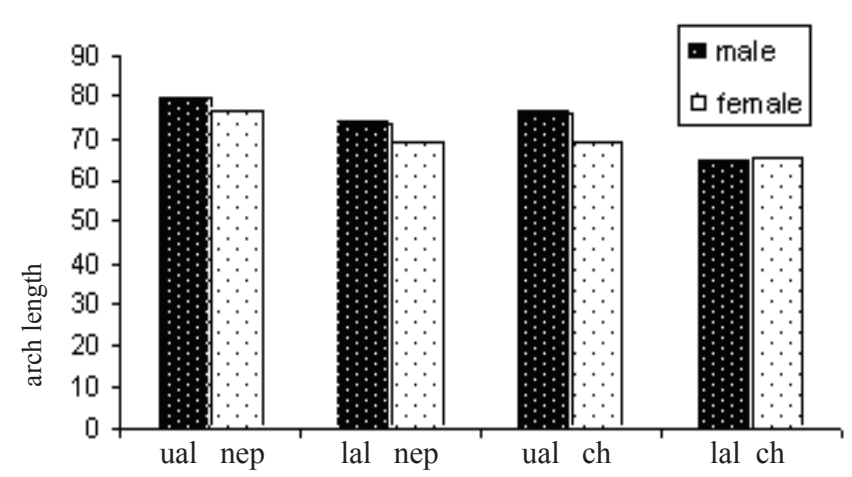

Fig.. 1 upper and lower arch length of Nepalese and Chinese male and female (ual: upper arch length, lal: lower arch length, nep: Nepalese, Ch: Chinese)

class III malocclusion are $79.5 \mathrm{~mm}$ and $77 \mathrm{~mm}$ respectively (Table 5). Mean lower arch length for Nepalese male and female with Angle class III malocclusion are $73.8 \mathrm{~mm}$ and $69.25 \mathrm{~mm}$. Mean upper arch length for Chinese male and female having Angle class III malocclusion are $76.18 \mathrm{~mm}$ and $69.25 \mathrm{~mm}$ respectively. Mean lower arch length for Chinese male and female with Angle class III malocclusion are $64.36 \mathrm{~mm}$ and $65.16 \mathrm{~mm}$ ( Fig .1). Correlation between upper arch length and lower arch length of both Nepalese male and female are low $(\mathrm{r}=0.163, \mathrm{r}=0.5$ respectively). Upper arch length for Chinese male and female having angle class III malocclusion are 76.18 and 69.25 respectively. Lower arch length
Table 6: AR and OR Mean, SD of Nepalese male and female

\begin{tabular}{lcrcc}
\hline OR/AR & Gender & Mean & SD & Significance \\
\hline OR & M & 91.9573 & 3.54637 & 0.074 \\
& F & 89.1332 & 2.27851 & \\
AR & M & 79.6357 & 5.36973 & 0.023 \\
& F & 78.0328 & 3.18585 & \\
\hline
\end{tabular}

( OR : Overall Ratio, AR : Anterior Ratio, $\mathrm{m}$ : male, f : female, SD : Standard Deviation)

Table 7: OR and AR, Mean, SD of Chinese male and female.

\begin{tabular}{llccc}
\hline OR/AR & Gender & Mean & SD & Significance \\
\hline OR & M & 89.2339 & 4.98998 & 0.302 \\
& F & 90.2285 & 3.74757 & \\
AR & M & 78.1045 & 3.92927 & 0.182 \\
& F & 78.2862 & 6.15238 & \\
\hline
\end{tabular}

(m : male, f: female, OR : Ovreall Ratio, AR : Anterior Ratio, SD : Standard Deviation)

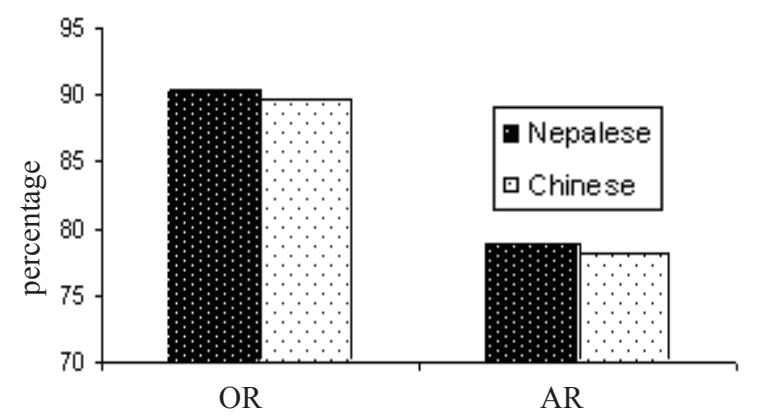

Figure 2. Diffference in OR and AR between Neplese and Chineses (OR and AR mean for Nepalese and Chinese)

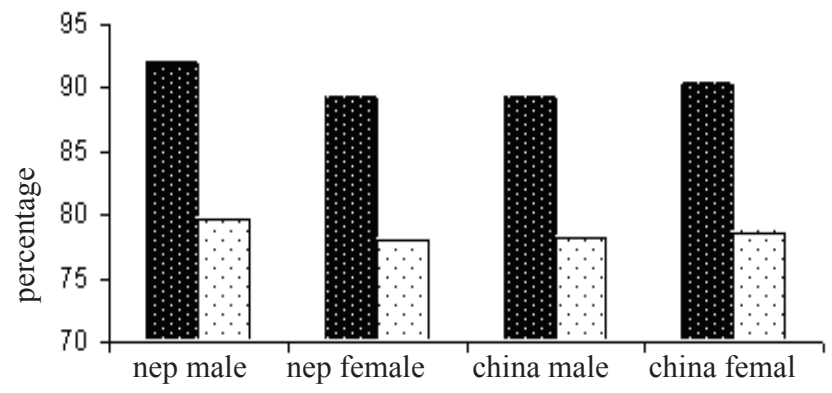

Figure3. Diffference in OR and AR between Neplese and Chineses (OR and AR mean for Nepalese and Chinese male and female)

for Chinese male and female with angle class III malocclusion are 64.36 and 65.16. The correlation between upper and lower arch length is high with correlation coefficient, $\mathrm{r}=0.608, \mathrm{r}=0.898$ respectively for Chinese male and female. No statistically significant difference in upper and lower arch length between Nepalese and Chinese. Among Nepalese significant difference in upper arch length between male and female but no significant 
Qu Hong et al.: Nepalese and Chinese Tooth Size and Arch Length in Angle Cass III Malocclusion

difference between male and female in lower arch length.

\section{Bolton ratio}

For Nepalese (Table 6)OR 90.42 and AR 78.76 while for Chinese (Table 7) OR 89.58 and AR 78.16 ( Fig .2). No significant difference between Chinese and Nepalese OR and AR. Nepalese class III malocclusion subject's OR out of $2 \mathrm{SD}$ from the Bolton standard was $14 \%$ (outside -2 SD $0 \%$ and outside +2 SD 14\%). AR outside Bolton 2 SD was $45.4 \%$ (outside -2 SD $13.6 \%$ and outside +2 SD $31.8 \%$ ). For Chinese class III malocclusion OR outside Bolton 2 SD 70.6\% (outside -2 SD 29.4\% and outside +2 SD 41.2\%) and AR outside 2 SD are $40.8 \%$ (outside -2 SD $29 \%$ and outside +2 SD 11.8\%). No significant difference between $\mathrm{OR}$ and $\mathrm{AR}$ for normal occlusion and class III malocclusion of Nepalese $(\mathrm{P}=0.251, \mathrm{P}=0.438)$. No significant difference between OR and AR for normal occlusion and class III malocclusion for Chinese $(\mathrm{P}=0.09, \mathrm{P}=0.58)$. No significant difference in $\mathrm{OR}$ between Nepalese male ( $\mathrm{OR}=91.95, \mathrm{AR}=79.63)$ and female $(\mathrm{OR}=89.13, \mathrm{AR}=78.03)$ but $\mathrm{AR}$ is significantly different $(\mathrm{P}=0.02)$. No significant difference between Chinese male $(\mathrm{OR}=89.23$, $\mathrm{AR}=78.28)$ and female $(\mathrm{OR}=90.22, \mathrm{AR}=78.50)$ (Fig.3) .

\section{Discussion}

\section{Tooth size difference}

Upper lateral incisor, upper canine and upper second premolar shows significant difference between Nepalese and Chinese $(\mathrm{P}=0.02$, $\mathrm{P}=.01, \mathrm{P}=.003$ ). Lower teeth show no significant difference between Nepalese and Chinese. Xia and $\mathrm{Wu}^{31)}$ studied on 1173 Han nationality and found no significant difference for the tooth size ratio between class III malocclusion group and other malocclusions as well as normal occlusion .Lavelle ${ }^{31}$, Nielin $^{32}$-shows class III cases with smaller maxillary tooth dimensions and bigger mandibular tooth.

\section{Tooth size difference between the sex}

Among Nepalese male and female lower lateral incisors, second premolar and lower molar show significant difference $(\mathrm{P}=0.035$, $\mathrm{P}=0.032, \mathrm{P}=0.049$ ). Upper second premolar shows significant difference between Nepalese male and female $(\mathrm{P}=0.020)$. Among Chinese male and female shows no significant difference between upper teeth while lower canine and lower first molar shows significant difference $(\mathrm{P}=0.041, \mathrm{P}=0.001)$.

Tancan $^{33)}$ in his study found that the mesiodistal tooth size, OR and AR are lager in male than in female in class III malocclusion group but found no significant sexual dimorphism for AR and OR among all malocclusion groups. Susan N. ${ }^{10)}$ in class III malocclusion several teeth were significantly smaller in females than in male, these teeth were maxillary first molar, mandibular 2nd premolar, mandibular 1st molar, canine and sum of mandibular and maxillary 12 teeth..

\section{Bolton ratio}

For Nepalese OR 90.42 and AR 78.76 while for Chinese OR 89.58 and AR 78.16. No significant difference between Chinese and
Nepalese OR and AR. No significant difference between OR and AR for normal occlusion and class III malocclusion of Nepalese $(\mathrm{P}=0.251$, $\mathrm{P}=0.438$ ). No significant difference between $\mathrm{OR}$ and $\mathrm{AR}$ for normal occlusion and class III malocclusion for Chinese ( $\mathrm{P}=0.09, \mathrm{P}=0.58)$ ${ }^{[7]}$. No significant difference in OR between Nepalese male and female but $A R$ is significantly different $(\mathrm{P}=0.02)$. No significant difference in AR and OR between Chinese male and female. Susan ${ }^{10)}$ found no statically significant difference in Bolton AR and OR between class III and other different occlusion categories. Nie Q $\operatorname{lin}^{32}$ shows that $\mathrm{AR}$ and $\mathrm{OR}$ of class III malocclusion were greater than that of other malocclusion.

\section{Arch length}

Upper arch length for Nepalese male and female having angle class III malocclusion are 79.5 and 77 respectively. Lower arch length for Nepalese male and female with angle class III malocclusion are 73.8 and 69.25. Upper arch length for Chinese male and female having angle class III malocclusion are 76.18 and 69.25 respectively. Lower arch length for Chinese male and female with angle class III malocclusion are 64.36 and 65.16. Correlation between upper arch length and lower arch length of both Nepalese male and female are low $(r=0.163, r=0.5$ respectively). Upper arch length for Chinese male and female having angle class III malocclusion are 76.18 and 69.25 respectively. Lower arch length for Chinese male and female with angle class III malocclusion are 64.36 and 65.16.The correlation between upper and lower arch length is high with correlation coefficient, $\mathrm{r}=0.608, \mathrm{r}=0.898$ for Chinese male and female respectively. No statistically significant difference in upper and lower arch length between Nepalese and Chinese. Among Nepalese significant difference in upper arch length between male and female but no significant difference between male and female in lower arch length. Susan ${ }^{10)}$ found that mandibular arch length in class III was significantly larger than class II division I and division II .

\section{Conclusion}

1. No significant differences were found in overall ratio and anterior ratio between Nepalese and Chinese having angle class III malocclusion $53 \%$ of the subjects were out of 2 SD of Bolton's OR, while $36 \%$ were out 2 SD of Bolton's AR.

2. No significant difference found between Chinese and Nepalese in $\mathrm{AR}$ and $\mathrm{OR}$. And also no significance difference between Nepalese male and female as well as Chinese male and female between AR and OR. So this indicates that Nepalese tooth size discrepancy is similar to that of Chinese for class III cases.

3. Low correlation was found between upper and lower arch length for Nepalese Male and female. Significant difference in upper arch length between Nepalese male and female with class III malocclusion. Lower arch length for Nepalese and both upper and lower arch length for Chinese showed no significant difference between male and female. 
4. Maxillary teeth showed higher variability than mandibular teeth for Nepalese while lower first molar showed higher variability in Chinese.

\section{Acknowledgement}

This work was supported by grant (No. 20041071) of Science and Technology of Liaoning province and by a grant (No. 20040104, 2005E21SF136) of educational department of Liaoning province and Dalian city, China. was also supported in parts by Grants-in Aid for Scientific Research (C) (No. 19592374 for Norimasa Okafuji and No.20592200 for Shin Takagi from the Japan Society for the Promotion of Science.

\section{References}

1. LittonSF, Ackermann LV, Isaacson RJ,et al. A genetic study of class 3 malocclusion AM J. orthodontics 58:565-77, 1970

2. Rokosi T, Schilli W. Class 3 anomalies: a coordinated approach to skeletal, dental and soft tissue problems. Journal of Oral Surgery 39:860-870, 1981

3. Peter Ngan, Stephen HY Wei. Early Treatment of Class 3 patients to improve facial esthetics and predict future growth. Dental Journal 1:28-34, 2004

4. Ishii H, Morita S, Takeuchi Y, et al. Treatment effect of combined maxillary protraction and chin cap appliance in sever skeletal class 3 cases. AM J. Orthodontics and Dentofascial Orthopedics 92:304-312, 1987.

5. Allwright WC, Burndred WH.A survey of handicapping dentofacial anomalies among Chinese in Hong Kong. International Dental Journal 14:505-519. 1964.

6. EL-Mangoury NH, Mostafa YA. Epidemiologic panorama of dental occlusion Angle Orthod .60:207-214, 1990.

7. Fu min kui. Fu Min kui : orthodontics. 4th edition peoples medical publishing house, 2006, pp167-168.

8. T.M. Graber, Orthodontics principles and practice. Third Edition. The United States of America, The C.V.Mosby Compang, 1985, pp205

9. Bhattarai et al,Rabindra man et al;Prevalence of malocclusion among nepalese orthodontic patients according to Angle's classification. Journal of Nepal Dental Association 9: 3234,2008 .

10. Susan N. AI-Khateeb, Elham S.J.Abu Alhaija. Tooth size discrepancies and arch parameters among different malocclusions in a Jordian samples Angle Orthod 76 :459465, 2006

11. Le RT. Arch width and for.:A review Am J Orthod dentofacial Orhtop 115:305-313, 1999

12.Black G. V. Discriptive anatomy of human teeth, ed.4,Philadelphia,S.S White Dental Mfg. Co.223-235, 1902

13. Basciftci FA Demir A, Uysal T,Sari Z. Prevalence of orthodontic malocclusion in Konya region school children. Turk ,J Ortho 15:(2): 92-98, 2002
14. Braun S,Hnat WP,Fender DE, Legan HL. The form of human dental arch .Angle Orthod 68:29-36, 1998

15. Brundtland GH,Liestol K, Walloe L.Height. Weight and menarcheal age of Oslo school children during the last 60 years. Ann Hum Biol 45: 307-322, 1980

16. Garn SM ,Osborne RH,Mc Cabe KD. The effect of prenatal factors on crown dimensions. Am J Phy Anthropol 51:665678, 1979.

17. Paynter KJ,Grainger RM . The relation of nutritionto the morphology and size of rat molar teeth.J Can Dent Assoc 22:519-531, 1956.

18. Crosby DR ,Alexander CG. The occurrence of tooth size discrepancies among different groups .Am J Orthod Dentofacial Orthod 95:457-461, 1989

19. Freeman JE, Maskeroni AJ ,Lorton L . Frequency of Bolton tooth size discrepancies among orthodontic patients. Am J Orthod Dentofacialb Orthop 110:24-27, 1996

20. Bolton WA. Disharmony in tooth size and it's relation to the analysis and treatment of malocclusion. Angle Orthod 28:113130,1958

21. Kestling HD. The philosophy of the tooth positioning appliance. Am J. Orthod 31:297-340,1945

22. NeFF CW. Size relation between the maxillary and mandibular anterior segment of the dental arch. Angle Orthod 27:138147,1957

23. NeFF CW. Tailored occlusion with the anterior coefficient. Am J Orthd 35; 309-313,1949

24. Bolton WA.The clinical application of a tooth size analysis. Am J Orthod 48:504-529, 1962

25. Lavelle CL, Flinn RM Foster TD, Hamilton MC.AN analysis into age changes of the human dental arch by a multivariate technique. Am J Phys Anthropol 33:403- 411, 1970

26. Lavelle CL Foster TD ,Flinn RM.Dental arch es in various ethnic groups. Angle Orthod 41:293-299, 1979

27. Bjork A Brown T Skieler V. Comprasion of craniofacial growth in Austrlian Aboriginal and Danes, illustrated by longitudinal cephalometric analysis. Eur J Orthod 6:1-14, 1984

28. Hassanali J,Odhiambo W. Analysis of dental casts of 6-8 and 12 years old Kenyan children. Eur J Orthod 22:135-142, 2000.

29. Yamada A, Nagahara K, Yuasa S .et al.A study of reliability in three dimensional measurement of a dental casts J Jpn Orthod Soc 46:18-31, 1987

30. Guvenc, Basaran; Murat Selek;Orhan Hamamc ;Zeki Akku . Intermaxillary Bolton Tooth size Discrepancies Among Different Malocclusion Angle Orthodontist 76: 26-30, 2005

31. Xia Z,Wu XY.The application of dentocclusal measurement in malocclusion Stomatology 3: 126-127, 1983

32. Nie Q, Lin J. Comparision of intermaxillary tooth size discrepancies among different malocclusion groups. Am J Orthod Dentofacial Orthop 116: 539-544,1999

33. Tancan Uysal ,Zafer Sari ,Faruk Ayhan Basciftci, Badel 
Qu Hong et al.: Nepalese and Chinese Tooth Size and Arch Length in Angle Cass III Malocclusion Memili. Intermaxillary tooth. size discrepancies and malocclusion:Is there a relation? The Angle Orthodontics 75: 208-213, 2004 
Journal of Hard Tissue Biology 17(2): 69-76, 2008 